\title{
The effects of airway pressure release ventilation on respiratory mechanics in extrapulmonary lung injury
}

\author{
Michaela Kollisch-Singule ${ }^{1}$, Bryanna Emr ${ }^{1}$, Sumeet V. Jain ${ }^{1}$, Penny Andrews ${ }^{2}$, Joshua Satalin ${ }^{*}$, Jiao Liu', \\ Elizabeth Porcellio', Van Kenyon', Guirong Wang ${ }^{1}$, William Marx', Louis A. Gatto ${ }^{1,3}$, Gary F. Nieman' \\ and Nader M. Habashi
}

\author{
* Correspondence: \\ satalinj@upstate.edu \\ ${ }^{1}$ Department of Surgery, SUNY \\ Upstate Medical University, $750 \mathrm{E}$. \\ Adams Street, Syracuse, NY 13210, \\ USA \\ Full list of author information is \\ available at the end of the article
}

\begin{abstract}
Background: Lung injury is often studied without consideration for pathologic changes in the chest wall. In order to reduce the incidence of lung injury using preemptive mechanical ventilation, it is important to recognize the influence of altered chest wall mechanics on disease pathogenesis. In this study, we hypothesize that airway pressure release ventilation (APRV) may be able to reduce the chest wall elastance associated with an extrapulmonary lung injury model as compared with low tidal volume (LVt) ventilation.
\end{abstract}

Methods: Female Yorkshire pigs were anesthetized and instrumented. Fecal peritonitis was established, and the superior mesenteric artery was clamped for 30 min to induce an ischemia/reperfusion injury. Immediately following injury, pigs were randomized into (1) LVt $(n=3)$, positive end-expiratory pressure (PEEP) $5 \mathrm{cmH}_{2} \mathrm{O}, V_{\mathrm{t}} 6 \mathrm{cc} \mathrm{kg}^{-1}, \mathrm{~F}_{\mathrm{i}} \mathrm{O}_{2} 21 \%$, and guided by the ARDSnet protocol or (2) APRV $(n=3), P_{\text {High }} 16-22 \mathrm{cmH}_{2} \mathrm{O}, P_{\text {Low }}$ $\mathrm{O} \mathrm{cmH}_{2} \mathrm{O}, T_{\text {High }} 4.5 \mathrm{~s}$, $T_{\text {Low }}$ set to terminate the peak expiratory flow at $75 \%$, and $\mathrm{F}_{\mathrm{i}} \mathrm{O}_{2}$ $21 \%$. Pigs were monitored continuously for 48 h. Lung samples and bronchoalveolar lavage fluid were collected at necropsy.

Results: LVt resulted in mild acute respiratory distress syndrome (ARDS) $\left(\mathrm{P}_{\mathrm{a}} \mathrm{O}_{2} /\right.$ $\left.\mathrm{F}_{\mathrm{i}} \mathrm{O}_{2}=226.2 \pm 17.1 \mathrm{mmHg}\right)$ whereas APRV prevented ARDS $\left(\mathrm{P}_{\mathrm{a}} \mathrm{O}_{2} / \mathrm{F}_{\mathrm{i}} \mathrm{O}_{2}=465.7 \pm\right.$ $66.5 \mathrm{mmHg} ; p<0.05)$. LVt had a reduced surfactant protein $A$ concentration and increased histologic injury as compared with APRV. The plateau pressure in APRV $\left(34.3 \pm 0.9 \mathrm{cmH}_{2} \mathrm{O}\right)$ was significantly greater than $\mathrm{LVt}\left(22.2 \pm 2.0 \mathrm{cmH}_{2} \mathrm{O} ; p<0.05\right)$ yet transpulmonary pressure between groups was similar $(p>0.05)$. This was because the pleural pressure was significantly lower in LVt $\left(7.6 \pm 0.5 \mathrm{cmH}_{2} \mathrm{O}\right)$ as compared with APRV $\left(17.4 \pm 3.5 \mathrm{cmH}_{2} \mathrm{O} ; p<0.05\right)$. Finally, the elastance of the lung, chest wall, and respiratory system were all significantly greater in LVt as compared with APRV (all $p<0.05$ ).

Conclusions: APRV preserved surfactant and lung architecture and maintenance of oxygenation. Despite the greater plateau pressure and tidal volumes in the APRV group, the transpulmonary pressure was similar to that of LVt. Thus, the majority of the plateau pressure in the APRV group was distributed as pleural pressure in this extrapulmonary lung injury model. APRV maintained a normal lung elastance and an open, homogeneously ventilated lung without increasing lung stress.

Keywords: Airway pressure release ventilation (APRV), Low tidal volume ventilation, Lung injury, Chest wall elastance, Transpulmonary pressure

\section{照 Springer}

(c) 2015 Kollisch-Singule et al. Open Access This article is distributed under the terms of the Creative Commons Attribution 4.0 International License (http://creativecommons.org/licenses/by/4.0/), which permits unrestricted use, distribution, and reproduction in any medium, provided you give appropriate credit to the original author(s) and the source, provide a link to the Creative Commons license, and indicate if changes were made. 


\section{Background}

Acute respiratory distress syndrome (ARDS) is a syndrome encompassing a broad range of phenotypes yet is often studied clinically as a single disease phenotype. ARDS can be broadly sub-classified into pulmonary versus extrapulmonary ARDS, the ultimate pathology of which may be similar; however, the etiology and physiology of the two subtypes are distinct [1]. Despite these physiologic differences, many of the randomized controlled trials evaluating the impact of ventilator strategies on the incidence and mortality of ARDS analyze patients with pulmonary and extrapulmonary ARDS combined, usually with a preponderance of pulmonary ARDS [2-8], and despite decades of study, the mortality associated with ARDS has not changed since 1994 [8]. Therefore, in order to establish strategies to improve ARDS incidence and mortality, it may be necessary to stratify patients according to ARDS physiology rather than generalizing ARDS as a single phenotype.

Patients with extrapulmonary ARDS are at particular risk for alterations in chest wall mechanics, whereas patients with pulmonary ARDS are less likely to have increases in chest wall elastance $\left(E_{\mathrm{cw}}\right)$, with the majority of the pathology associated with increased lung elastance $\left(E_{1}\right)$. The mechanism of increased chest wall elastance in extrapulmonary ARDS is a combination of chest wall edema and increased intra-abdominal pressure (IAP). In patients with normal $E_{\mathrm{cw}}$, airway opening pressure closely resembles the lung-distending (transpulmonary) pressure, but in patients with an increase in $E_{\mathrm{cw}}$, a greater portion of the airway opening pressure is generated as pleural pressure, leading to a lower transpulmonary pressure [9]. Chest wall elastance represents only a small fraction of the respiratory system elastance $\left(E_{\mathrm{rs}}\right)$ in patients with ARDS with normal chest wall elastance [9]; however, in patients with altered chest wall mechanics, the $E_{\mathrm{cw}}$ to $E_{\mathrm{rs}}$ ratio ranges from 20 to $80 \%$ [10]. This great variability demonstrates the fallibility of targeting airway opening pressures without taking the $E_{\mathrm{cw}}$ and transpulmonary pressure into consideration.

In previous animal studies of extrapulmonary ARDS, airway pressure release ventilation (APRV) was associated with higher tidal volumes and plateau pressures [11, 12], which has raised concern for APRV potentially placing undue stress on the lung. In this study, we use esophageal manometry to measure transpulmonary pressure between preemptive application of APRV and low tidal volume ventilation in our clinically applicable porcine extrapulmonary ARDS model. We demonstrate that the transpulmonary pressures are similar between the two ventilation strategies, despite the increased tidal volumes and plateau pressures in the APRV group, and that APRV was able to limit increases in chest wall elastance.

\section{Methods}

All experiments were performed in accordance with National Institutes of Health guidelines in the use of laboratory animals and approved by the SUNY Upstate Medical University Institutional Animal Care and Use Committee (IACUC). The study was terminated upon achieving statistical significance between the two groups, according to the IACUC guidelines and study protocol. Female Yorkshire pigs (32-36 kg) were anesthetized using a continuous infusion of ketamine/xylazine to maintain a surgical plane of anesthesia. Animals were continuously monitored by the investigators for the duration of the experiment. Under sterile conditions, animals underwent tracheostomy and arterial and venous catheterization. The animals were connected to a Dräger (Evita Infinity V500, Lübeck, Germany) ventilator and ventilated initially with $\left(V_{\mathrm{t}}\right) 10 \mathrm{cc} \mathrm{kg}^{-1}$, positive end- 
expiratory pressure (PEEP) of $5 \mathrm{cmH}_{2} \mathrm{O}$, respiratory rate (RR) of 12 breaths $\mathrm{min}^{-1}$, and $\mathrm{F}_{\mathrm{i}} \mathrm{O}_{2} 100 \%$.

A pulse index continuous cardiac output (PiCCO) catheter (Pulsion Medical Systems, Germany) was placed in the femoral artery with hourly injections to assess cardiac index and global end-diastolic index. A cystostomy was performed for continuous urine output and hourly IAP monitoring (ConvaTec Inc. NJ). Intra-abdominal hypertension was defined as sustained or repeated elevation in IAP $(>12 \mathrm{mmHg})$ and abdominal compartment syndrome as repeated elevation in IAP $(>20 \mathrm{mmHg})$ associated with new organ dysfunction according to consensus criteria [13]. The esophageal catheter was placed by first advancing the balloon into the stomach, where placement was confirmed by a transient increase in pressure during abdominal compression, then retracting it to the middle third of the esophagus with placement confirmed by noting cardiac oscillation and respiratory variation in the waveform [14]. Baseline (BL) measurements were taken after surgical preparation and prior to injury.

Extrapulmonary lung injury was induced using a previously established double-hit model of ischemia reperfusion and fecal peritonitis [11, 12, 15]. Briefly, the superior mesenteric artery was clamped for $30 \mathrm{~min}$ and released to induce intestinal ischemia. Peritoneal sepsis was induced by performing a cecotomy and mixing feces with blood to create a fecal clot, which was then implanted into the peritoneum. Time zero (T0) measurements were taken immediately after induction of the double-hit injury and upon closure of the abdomen. The animals were subsequently randomized into two groups: low tidal volume (LVt) ventilation or APRV.

LVt group $(n=3)$ : Animals were transitioned from the baseline settings to low tidal volume settings of $V_{\mathrm{t}} 6 \mathrm{cc} \mathrm{kg}^{-1}$, PEEP of $5 \mathrm{cmH}_{2} \mathrm{O}, \mathrm{RR} 12$ breaths $\mathrm{min}^{-1}$, and $\mathrm{F}_{\mathrm{i}} \mathrm{O}_{2} 21 \%$. All ventilator adjustments were made in accordance with the ARDSnet guidelines with PEEP and $\mathrm{F}_{\mathrm{i}} \mathrm{O}_{2}$ titrated according to $\mathrm{SpO}_{2}$ and $\mathrm{P}_{\mathrm{a}} \mathrm{O}_{2}$ as outlined by the "Lower PEEP/higher $\mathrm{F}_{\mathrm{i}} \mathrm{O}_{2}$ scale". $\mathrm{RR}$ was titrated according to $\mathrm{pH}$ and $\mathrm{P}_{\mathrm{a}} \mathrm{CO}_{2}$ and $V_{\mathrm{t}}$ was reduced to accommodate the plateau pressure $\left(P_{\text {plat }}\right)$ if values exceed $30 \mathrm{cmH}_{2} \mathrm{O}$.

APRV group $(n=3)$ : APRV was applied and guided using a previously described protocol by Habashi [16]. Animals were ventilated at an inspiratory pressure $P_{\text {High }}$ set at the $P_{\text {plat }}$ established during the volume cycle setting used for BL measurements $\left(16-22 \mathrm{cmH}_{2} \mathrm{O}\right)$ for a time $\left(T_{\text {High }}\right)$ of $4.0-4.5 \mathrm{~s}$, which was set to occupy approximately $90 \%$ of the total ventilator cycle time. The release pressure $\left(P_{\text {Low }}\right)$ was set at $0 \mathrm{cmH}_{2} \mathrm{O}$ to minimize expiratory resistance and maximize the peak expiratory flow rate. $P_{\text {Low }}$ was applied for a time $\left(T_{\text {Low }}\right)$ to terminate the endexpiratory flow rate at $75 \%$ of the peak expiratory flow rate, which was between 0.32 and 0.37 s. $P_{\text {High }}, T_{\mathrm{High}}, T_{\text {Low }}$, and $\mathrm{F}_{\mathrm{i}} \mathrm{O}_{2}$ were titrated throughout the study according to pulmonary parameters, $\mathrm{P}_{\mathrm{a}} \mathrm{O}_{2}$ and $\mathrm{P}_{\mathrm{a}} \mathrm{CO}_{2}$.

\section{Resuscitative protocol}

Antibiotics, fluid, and vasopressor administration were guided by the Surviving Sepsis campaign [17]. Broad-spectrum antibiotics (vancomycin $1 \mathrm{~g}$ and piperacillin/tazobactam $3.375 \mathrm{~g}$ ) were administered following abdominal closure and throughout the study every 12 and $8 \mathrm{~h}$, respectively. Animals were provided with continuous maintenance intravenous fluid resuscitation and boluses as needed with Lactated Ringers to maintain 
a mean arterial pressure (MAP) $>65 \mathrm{mmHg}$. Continuous infusion of norepinephrine was initiated when the animal was no longer fluid responsive, followed by vasopressin and epinephrine. Rocuronium was initiated if spontaneous respiratory effort was demonstrated in order to standardize animals across groups.

\section{Physiologic measurements}

Hemodynamics were monitored continuously (Intellivue MP-90, Phillips Healthcare, Irvine, CA) using Edwards transducers (Pressure Monitoring Kit, Edwards Lifesciences, Irvine, CA). Blood gases were measured every $1-3 \mathrm{~h}$ with a Roche blood gas analyzer (Cobas b221, Basel, Switzerland).

\section{Pulmonary parameters}

Pulmonary parameters were measured or calculated by the Dräger ventilator. The endexpiratory pressure in APRV was taken to be the lowest value during the expiratory release phase after accounting for tracheal tube compensation. The respiratory system may be partitioned into the lung and the chest wall, and the plateau pressure $\left(P_{\text {plat }}\right)$ distributed across the respiratory system may also be divided into the corresponding transpulmonary pressure $\left(P_{1}\right)$ and pleural pressure $\left(P_{\mathrm{pl}}\right)[18,19]$.

$$
P_{\text {plat }}=P_{1}+P_{\mathrm{pl}}
$$

Similarly, the sum of the lung $\left(E_{1}\right)$ and chest wall $\left(E_{\mathrm{cw}}\right)$ elastance represents the elastance of the entire respiratory system $\left(E_{\mathrm{rs}}\right)$ (Eq. 2) [18].

$$
E_{\mathrm{rs}}=E_{\mathrm{cw}}+E_{1}
$$

The elastance calculated by the ventilator (standardly reported as compliance on the monitor) represents the elastance of the respiratory system (Eq. 3) but does not distinguish lung from chest wall elastance.

$$
E_{\mathrm{rs}}=\left(P_{\text {plat }}-\mathrm{PEEP}\right) / V_{\mathrm{t}}
$$

The use of esophageal manometry to determine the partitioning of respiratory system elastance into chest wall and lung elastance was first described in a thesis by Buytendijk in 1949 [20, 21] although several methods of direct [22, 23] and indirect [14, 24, 25] measurements have since been described. The change in $P_{\mathrm{es}}$ between inspiration and expiration $\left(\Delta P_{\mathrm{Es}}\right)$ approximates the change in $P_{\mathrm{pl}}[26,27]$; thus, the elastance of the chest wall may be calculated as follows [28]:

$$
\Delta P_{\mathrm{Es}} / V_{\mathrm{t}}=E_{\mathrm{cw}}
$$

Therefore, the distribution of $P_{\mathrm{aw}}$ to the lung $\left(P_{1}\right)$ and chest wall $\left(P_{\mathrm{pl}}\right)$ can be calculated based on the ratios of lung elastance and chest wall elastance to the respiratory system elastance, respectively (Eqs. 5 and 6) $[9,18]$.

$$
\begin{aligned}
& P_{\mathrm{pl}}=P_{\text {plat }} \cdot\left(E_{\mathrm{cw}} / E_{\mathrm{rs}}\right) \\
& P_{1}=P_{\text {plat }} \cdot\left(E_{\mathrm{l}} / E_{\mathrm{rs}}\right)
\end{aligned}
$$

\section{Necropsy}

After $48 \mathrm{~h}$, the experimental protocol was terminated. Animals were euthanized with Fatal-Plus (1 mL $10 \mathrm{lbs}^{-1}$ intravenous), cardiac death confirmed, and necropsy performed. 
The lungs were removed and inflated to $25 \mathrm{cmH}_{2} \mathrm{O}$, using stepwise increases in PEEP to standardize lung volume history, and grossly photographed. The left lung was filled with $10 \%$ formalin to a height of $25 \mathrm{cmH}_{2} \mathrm{O}$, clamped and submerged in formalin. The right middle lobe was lavaged with $60 \mathrm{~mL}$ of normal saline to collect bronchoalveolar lavage fluid (BALF). The concentrations of interleukin- 6 and -8 (IL-6 and IL-8) were determined using enzyme-linked immunosorbent assay (ELISA) quantification according to manufacturer's recommendations. Western blot analyses of surfactant protein A (SP-A) and B (SP-B) abundance as well as determination of total protein were performed as described previously [11].

\section{Quantitative histology}

The quantitative histological assessment of the lung was based on image analysis of 120 photomicrographs (10 per animal) made at high-dry magnification following a validated, blinded, systematic sampling protocol [15]. Each photomicrograph was scored using a 4-point scale for each of the five parameters: atelectasis, fibrinous deposits and blood in air space, vessel congestion, alveolar wall thickness, and leukocytes.

\section{Statistics}

The study was terminated upon achieving statistical significance between the two groups, according to the IACUC guidelines to reduce the number of animals used for experimentation and the study protocol. Data are reported as mean \pm SEM. Repeated measures ANOVA was used to compare differences within and between treatment groups for continuous parameters and post hoc Tukey's tests if significance was found in the group*time effect. Categorical data were compared using an unpaired Student's $t$ test. Quantitative histological assessment was analyzed using Mann-Whitney $U$ test after testing for normality. $p$ values $<0.05$ were considered significant. Analyses were performed using JMP (version 10, Cary, NC).

\section{Results}

\section{Hemodynamics}

Both LVt and APRV pigs had a precipitous decline in MAP in the hour following injury with a steady decline thereafter (Table 1). The MAP was similar in both groups and was maintained above $65 \mathrm{mmHg}$ with fluid and vasopressor support $(p>0.05)$. The total volume of fluid infused over the course of the experiment was similar between LVt $(36.0 \pm 7.5 \mathrm{~L})$ and APRV $(47.8 \pm 7.2 \mathrm{~L} ; p>0.05$; Table 1$)$. The cardiac index (LVt $3.3 \pm 0.7 \mathrm{~L} \mathrm{~min}{ }^{-1} \mathrm{~m}^{-2}$; APRV $2.0 \pm 0.3 \mathrm{~L} \mathrm{~min}^{-1} \mathrm{~m}^{-2}$ ) and global end-diastolic index (LVt $563.7 \pm 167.8 \mathrm{~mL} \cdot \mathrm{min}^{-2}$; APRV $314.0 \pm 111.9 \mathrm{~mL} \cdot \mathrm{min}^{-2}$ ), as measured by the PiCCO catheter, were similar between groups $(p>0.05$; Table 1$)$.

\section{Pulmonary data}

The end-expiratory release pressure was significantly greater in APRV as compared with LVt $\left(p<0.05\right.$; Table 2), despite a $P_{\text {Low }}$ of $0 \mathrm{cmH}_{2} \mathrm{O}$, demonstrating the importance of setting the $T_{\text {Low }}$ appropriately to ensure the end-expiratory pressure never has the time to actually reach $0 \mathrm{cmH}_{2} \mathrm{O}$. Consistent with previous studies [11, 29], the tidal volumes in the APRV group (13.3. $\pm 0.6 \mathrm{cc} \mathrm{kg}^{-1}$ ) were significantly greater than those in 
Table 1 Hemodynamic data and organ injury in low tidal volume (LVt) versus airway pressure release ventilation (APRV)

\begin{tabular}{|c|c|c|c|c|c|c|c|}
\hline & & Baseline & $12 \mathrm{~h}$ & $24 \mathrm{~h}$ & $36 \mathrm{~h}$ & $48 \mathrm{~h}$ & $p$ value \\
\hline MAP & $\mathrm{LVt}$ & $123.7 \pm 15.8$ & $73.3 \pm 3.3$ & $77.7 \pm 2.7$ & $76.3 \pm 4.3$ & $71.3 \pm 3.3$ & 0.0811 \\
\hline$(\mathrm{mmHg})$ & APRV & $109.3 \pm 5.2$ & $86.7 \pm 3.9$ & $69.0 \pm 1.2$ & $73.0 \pm 1.2$ & $72.7 \pm 1.5$ & \\
\hline Cardiac index & $\mathrm{LVt}$ & $3.2 \pm 0.6$ & $2.6 \pm 0.3$ & $2.4 \pm 0.2$ & $3.7 \pm 0.4$ & $3.3 \pm 0.7$ & 0.8551 \\
\hline$\left(L \min ^{-1} \mathrm{~m}^{-2}\right)$ & APRV & $2.8 \pm 0.5$ & $2.0 \pm 0.1$ & $2.1 \pm 0.1$ & $2.5 \pm 0.3$ & $2.0 \pm 0.3$ & \\
\hline $\begin{array}{l}\text { Global end-diastolic } \\
\text { index }\end{array}$ & $\mathrm{LVt}$ & $596.0 \pm 78.0$ & $528.0 \pm 139.9$ & $467.7 \pm 135.3$ & $543.0 \pm 145.0$ & $563.7 \pm 167.8$ & 0.0604 \\
\hline$\left(\mathrm{mL} \min ^{-2}\right)$ & APRV & $475.7 \pm 141.9$ & $484.7 \pm 146.5$ & $407.0 \pm 129.0$ & $391.3 \pm 116.4$ & $314.0 \pm 111.9$ & \\
\hline $\begin{array}{l}\text { Intra-abdominal } \\
\text { pressure }\end{array}$ & $\mathrm{LVt}$ & $2.3 \pm 1.6$ & $13.6 \pm 2.4$ & $11.8 \pm 2.0$ & $13.1 \pm 4.5$ & $11.3 \pm 5.0$ & $<0.0001$ \\
\hline$\left(\mathrm{cmH}_{2} \mathrm{O}\right)$ & APRV & $0.9 \pm 0.5$ & $15.0 \pm 2.1$ & $19.5 \pm 2.4$ & $25.8 \pm 8.5$ & $21.8 \pm 0.8$ & \\
\hline \multirow{2}{*}{$\begin{array}{l}\text { Cumulative urine } \\
\text { output (L) }\end{array}$} & $\mathrm{LVt}$ & $0.8 \pm 0.7$ & $3.8 \pm 0.9$ & $6.2 \pm 1.2$ & $9.1 \pm 1.2$ & $16.7 \pm 5.0$ & 0.599 \\
\hline & APRV & $0.5 \pm 0.2$ & $2.4 \pm 0.4$ & $4.6 \pm 0.7$ & $7.3 \pm 0.8$ & $9.1 \pm 1.1$ & \\
\hline \multirow{2}{*}{$\begin{array}{l}\text { Urine output } \\
\left(\mathrm{mL} \mathrm{kg}^{-1}\right)\end{array}$} & LVt & $22.2 \pm 18.2$ & $6.4 \pm 2.0$ & $5.0 \pm 1.5$ & $6.3 \pm 1.1$ & $12.2 \pm 6.9$ & 0.5469 \\
\hline & APRV & $14.4 \pm 4.0$ & $4.0 \pm 1.4$ & $6.8 \pm 1.3$ & $4.9 \pm 0.6$ & $2.5 \pm 0.5$ & \\
\hline \multirow{2}{*}{$\begin{array}{l}\text { Cumulative fluids } \\
\text { administered }(L)\end{array}$} & LVt & $2.1 \pm 0.3$ & $11.9 \pm 1.7$ & $19.2 \pm 2.9$ & $25.7 \pm 3.9$ & $36.0 \pm 7.5$ & 0.3266 \\
\hline & APRV & $1.5 \pm 0.1$ & $14.3 \pm 0.5$ & $22.9 \pm 0.5$ & $32.5 \pm 0.7$ & $47.8 \pm 7.2$ & \\
\hline Blood urea nitrogen & $\mathrm{LVt}$ & $5.0 \pm 0.4$ & $7.3 \pm 1.2$ & $8.7 \pm 2.4$ & $9.1 \pm 2.7$ & $7.7 \pm 1.9$ & 0.9543 \\
\hline$\left(m g d L^{-1}\right)$ & APRV & $5.7 \pm 0.5$ & $7.0 \pm 0.5$ & $9.2 \pm 0.8$ & $11.8 \pm 1.2$ & $11.1 \pm 2.8$ & \\
\hline
\end{tabular}

Only intra-abdominal pressure was significant between groups over time; however, there was no significant difference at any individual time point

the LVt group (5.6 $\pm 0.3 \mathrm{cc} \mathrm{kg}^{-1} ; p<0.05$; Table 2). In one LVt animal, the $P_{\text {plat }}$ became greater than $30 \mathrm{cmH}_{2} \mathrm{O}$ at T43 (although the corresponding transpulmonary pressures was $23.9 \mathrm{cmH}_{2} \mathrm{O}$ ) and the $V_{\mathrm{t}}$ was decreased to maintain $P_{\text {plat }}$ below $30 \mathrm{cmH}_{2} \mathrm{O}$ as per the ARDSnet protocol [3]; however, this led to prompt desaturation $\left(\mathrm{SpO}_{2}<88 \%\right)$ that ultimately required titrating PEEP and $\mathrm{F}_{\mathrm{i}} \mathrm{O}_{2}$ upward (requiring an $\mathrm{F}_{\mathrm{i}} \mathrm{O}_{2}$ of $50 \%$ and a PEEP of $10 \mathrm{cmH}_{2} \mathrm{O}$ to maintain adequate oxygen saturation by T48). By the study end, LVt animals had significantly greater $\mathrm{F}_{\mathrm{i}} \mathrm{O}_{2}$ requirements $(37.7 \pm 6.7 \%)$ as compared with the APRV pigs, all of which were maintained on an $\mathrm{F}_{\mathrm{i}} \mathrm{O}_{2}$ of $21 \%$ throughout the study $\left(21.0 \pm 0.0 \% ; p<0.05\right.$; Table 2). Significant differences in the $\mathrm{P}_{\mathrm{a}} \mathrm{O}_{2} / \mathrm{F}_{\mathrm{i}} \mathrm{O}_{2}$ ratio between APRV and LVt were revealed by T30 and persisted until T48 with final $\mathrm{P}_{\mathrm{a}} \mathrm{O}_{2} /$ $\mathrm{F}_{\mathrm{i}} \mathrm{O}_{2}$ ratio of $226.2 \pm 17.1$ in LVt and $465.7 \pm 66.5$ in APRV $(p<0.05)$ with all animals in the LVt group meeting the Berlin criteria for mild ARDS [30] by T36 (Table 2).

The plateau pressures in both groups increased steadily over the course of the study with a significantly lower plateau pressure in LVt $\left(22.2 \pm 2.0 \mathrm{cmH}_{2} \mathrm{O}\right)$ as compared with APRV $\left(34.3 \pm 0.9 \mathrm{cmH}_{2} \mathrm{O} ; p<0.05\right.$; Table 2). Over time, the $P_{\mathrm{pl}}$ in APRV increased from $5.5 \pm$ $1.0 \mathrm{cmH}_{2} \mathrm{O}$ at T0 to $17.4 \pm 3.5 \mathrm{cmH}_{2} \mathrm{O}$ at T48 whereas the $P_{\mathrm{pl}}$ in LVt remained relatively stable from $4.0 \pm 1.3$ to $7.6 \pm 0.5 \mathrm{cmH}_{2} \mathrm{O}$ leading to a significant difference between the two groups by T48 $(p<0.05$; Fig. 1$)$. The $P_{1}$ in the LVt group $\left(14.6 \pm 2.1 \mathrm{cmH}_{2} \mathrm{O}\right)$ was similar to that of the APRV group $\left(17.3 \pm 2.9 \mathrm{cmH}_{2} \mathrm{O} ; p>0.05\right)$. In combination, these data suggest that the majority of the increased $P_{\text {plat }}$ in APRV was being distributed as $P_{\mathrm{pl}}$, directed towards the chest wall, rather than increasing lung stress. Finally, the elastance of the lung, chest wall, and respiratory system were all significantly greater in LVt as compared with APRV (all $p<0.05$; Table 2). By the end of the 48-h study, the lung elastance increased by $154 \pm 78 \%$ in the LVt group but was reduced by $43.2 \pm 5.2 \%$ in the APRV group. 
Table 2 Pulmonary data in low tidal volume (LVt) versus airway pressure release ventilation (APRV)

\begin{tabular}{|c|c|c|c|c|c|c|c|}
\hline & & Baseline & $12 \mathrm{~h}$ & $24 \mathrm{~h}$ & $36 \mathrm{~h}$ & $48 \mathrm{~h}$ & $p$ value \\
\hline \multirow[t]{2}{*}{ Plateau pressure $\left(\mathrm{cmH}_{2} \mathrm{O}\right)$} & $\mathrm{LVt}$ & $16.7 \pm 2.7$ & $14.5 \pm 0.5$ & $18.2 \pm 1.1$ & $22.0 \pm 1.9$ & $22.2 \pm 2.0$ & $0.0188 \S$ \\
\hline & APRV & $18.2 \pm 2.2$ & $22.8 \pm 2.5^{*}$ & $27.0 \pm 0.6^{*}$ & $31.0 \pm 0.6^{*}$ & $34.3 \pm 0.9^{*}$ & \\
\hline \multirow{2}{*}{$\begin{array}{l}\text { Transpulmonary pressure } \\
\left(\mathrm{cmH}_{2} \mathrm{O}\right)\end{array}$} & $\mathrm{LVt}$ & $12.7 \pm 3.8$ & $9.6 \pm 1.7$ & $11.2 \pm 0.1$ & $13.8 \pm 1.7$ & $14.9 \pm 1.9$ & 0.1116 \\
\hline & APRV & $12.7 \pm 3.2$ & $12.6 \pm 1.3$ & $16.4 \pm 1.5$ & $14.6 \pm 2.1$ & $17.3 \pm 2.9$ & \\
\hline \multirow[t]{2}{*}{ Pleural pressure $\left(\mathrm{cmH}_{2} \mathrm{O}\right)$} & LVt & $3.9 \pm 1.3$ & $4.9 \pm 1.4$ & $6.9 \pm 1.1$ & $8.2 \pm 0.3$ & $7.6 \pm 0.5$ & $<0.0001 \S$ \\
\hline & APRV & $5.5 \pm 1.0$ & $10.2 \pm 1.2^{*}$ & $10.6 \pm 1.2$ & $16.1 \pm 1.4^{*}$ & $17.4 \pm 3.5^{*}$ & \\
\hline \multirow{2}{*}{$\begin{array}{l}\text { End-expiratory pressure } \\
\text { (set) }\left(\mathrm{cmH}_{2} \mathrm{O}\right)\end{array}$} & $\mathrm{LVt}$ & $5.0 \pm 0.0$ & $5.0 \pm 0.0$ & $5.0 \pm 0.0$ & $6.0 \pm 1.0$ & $6.6 \pm 1.7$ & $<0.0001 \S$ \\
\hline & APRV & $0.0 \pm 0.0^{*}$ & $0.0 \pm 0.0^{*}$ & $0.0 \pm 0.0^{*}$ & $0.0 \pm 0.0^{*}$ & $0.0 \pm 0.0^{*}$ & \\
\hline \multirow{2}{*}{$\begin{array}{l}\text { End-expiratory pressure } \\
\text { (measured) }\left(\mathrm{cmH}_{2} \mathrm{O}\right)\end{array}$} & LVt & $5.1 \pm 0.1$ & $5.0 \pm 0.1$ & $5.2 \pm 0.1$ & $6.2 \pm 1.2$ & $6.6 \pm 1.7$ & $<0.0001 \S$ \\
\hline & APRV & $5.1 \pm 0.1$ & $10.7 \pm 0.9^{*}$ & $11.8 \pm 0.6^{*}$ & $14.2 \pm 1.1^{*}$ & $17.8 \pm 2.0^{*}$ & \\
\hline \multirow[t]{2}{*}{ Tidal volume $\left(\mathrm{cc} \mathrm{kg}^{-1}\right)$} & LVt & $10.2 \pm 0.1$ & $6.0 \pm 0.0$ & $6.0 \pm 0.0$ & $5.9 \pm 0.0$ & $5.6 \pm 0.3$ & $<0.0001 \S$ \\
\hline & APRV & $10.0 \pm 0.1$ & $9.7 \pm 0.3^{*}$ & $11.0 \pm 0.8^{*}$ & $12.3 \pm 0.6^{*}$ & $13.30 .6^{*}$ & \\
\hline \multirow{2}{*}{$\begin{array}{l}\text { Respiratory system } \\
\text { elastance }\left(\mathrm{cmH}_{2} \mathrm{O} \mathrm{L}^{-1}\right)\end{array}$} & LVt & $31.2 \pm 7.9$ & $43.5 \pm 4.2$ & $59.8 \pm 6.3$ & $72.8 \pm 8.3$ & $76.4 \pm 9.4$ & $<0.0001 \S$ \\
\hline & APRV & $35.8 \pm 6.0$ & $34.2 \pm 4.8$ & $38.5 \pm 5.5$ & $38.0 \pm 5.6^{*}$ & $33.4 \pm 4.6^{*}$ & \\
\hline \multirow{2}{*}{$\begin{array}{l}\text { Lung elastance } \\
\left(\mathrm{cmH}_{2} \mathrm{O} \mathrm{L}^{-1}\right)\end{array}$} & $\mathrm{LVt}$ & $24.4 \pm 9.4$ & $29.3 \pm 6.7$ & $36.7 \pm 1.6$ & $45.7 \pm 6.3$ & $50.3 \pm 8.3$ & $<0.0001 \S$ \\
\hline & APRV & $29.7 \pm 6.6$ & $18.8 \pm 2.6$ & $23.8 \pm 5.1$ & $18.8 \pm 4.8^{*}$ & $17.6 \pm 5.1^{*}$ & \\
\hline \multirow{2}{*}{$\begin{array}{l}\text { Chest wall elastance } \\
\left(\mathrm{cmH}_{2} \mathrm{OL}^{-1}\right)\end{array}$} & LVt & $6.8 \pm 1.9$ & $14.2 \pm 3.9$ & $23.1 \pm 4.8$ & $27.0 \pm 2.6$ & $26.2 \pm 2.9$ & $0.0377 \S$ \\
\hline & APRV & $10.6 \pm 1.8$ & $15.4 \pm 2.3$ & $14.7 \pm 1.0$ & $19.2 \pm 1.1^{*}$ & $15.8 \pm 0.5^{*}$ & \\
\hline \multirow[t]{2}{*}{$\mathrm{FiO}_{2}(\%)$} & LVt & $1.00 \pm 0.00$ & $0.24 \pm 0.03$ & $0.27 \pm 0.05$ & $0.33 \pm 0.03$ & $0.37 \pm 0.07$ & $<0.0001 \S$ \\
\hline & APRV & $1.00 \pm 0.00$ & $0.21 \pm 0.00$ & $0.21 \pm 0.00$ & $0.21 \pm 0.00^{*}$ & $0.21 \pm 0.00$ & \\
\hline \multirow[t]{2}{*}{$\mathrm{P}_{\mathrm{a}} \mathrm{O}_{2} / \mathrm{FiO}_{2}(\mathrm{mmHg})$} & $\mathrm{LVt}$ & $\begin{array}{l}550.4 \pm \\
20.1\end{array}$ & $\begin{array}{l}429.4 \pm \\
36.6\end{array}$ & $\begin{array}{l}411.3 \pm \\
39.2\end{array}$ & $\begin{array}{l}269.6 \pm \\
6.4\end{array}$ & $\begin{array}{l}226.2 \pm \\
17.1\end{array}$ & $<0.0001 \S$ \\
\hline & APRV & $\begin{array}{l}556.8 \pm \\
27.4\end{array}$ & $\begin{array}{l}443.5 \pm \\
29.4\end{array}$ & $\begin{array}{l}416.8 \pm \\
26.5\end{array}$ & $\begin{array}{l}374.6 \pm \\
13.8^{*}\end{array}$ & $\begin{array}{l}465.7 \pm \\
66.5^{*}\end{array}$ & \\
\hline
\end{tabular}

The end-expiratory pressure set on the ventilator with LVt (PEEP) and APRV $\left(P_{\text {Low }}\right)$ are distinguished from the actual endexpiratory pressure measured at the level of the trachea. $p$ value (right column) following RM ANOVA with ${ }^{5} p<0.05$ considered significant. * $p<0.05 \mathrm{LVt}$ versus APRV following post hoc analysis with Tukey's test

\section{Organ injury}

Animals in the APRV group had an increase in IAP $\left(21.8 \pm 0.8 \mathrm{cmH}_{2} \mathrm{O}\right)$ as compared with LVt $\left(11.3 \pm 5.0 \mathrm{cmH}_{2} \mathrm{O} ; p<0.05\right.$; Table 1), consistent with the increase in $P_{\mathrm{pl}}$ seen in APRV. Despite the measured increased IAP in APRV, there was no clinical evidence of reduced end-organ perfusion in either group and no animal required a decompressive laparotomy for abdominal compartment syndrome. Both groups had similar

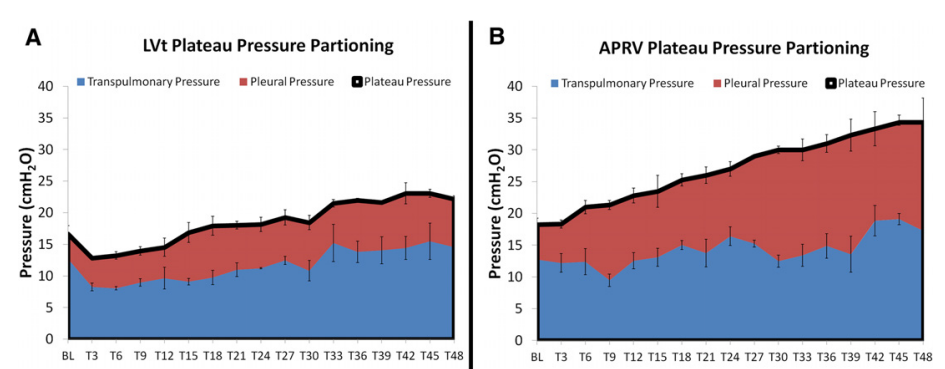

Fig. 1 The plateau pressure (black line at top of the red area curve) in LVt (a) is significantly lower than that of APRV (b) yet the transpulmonary pressures (blue) are statistically similar between groups. This demonstrates that the increases in plateau pressure in APRV reflects and increase in pleural pressure (red) 
blood urea nitrogen levels, and the total urine output between the two groups was similar $(p>0.05$; Table 1$)$.

\section{Gross pathology and quantitative histology}

The lungs of the LVt group inflated heterogeneously with predominant basilar and dependent atelectasis; the majority of which could be recruited with persistent pressure (Fig. 2a). The cut surfaces of the LVt group were erythematous and had both interlobular septal edema and bronchial edema (Fig. 2b). The lungs of the APRV group were pink, light, and inflated homogeneously (Fig. 2c), and the cut surface of the lung demonstrated interlobular septal edema but little bronchial edema (Fig. 2d). Two of the three pigs in each group demonstrated small bowel dilatation consistent with ileus as well as bowel wall edema. All of the pigs in both groups demonstrated gastric ulceration ranging from hyperemia to gross hemorrhagic ulcers. The wet-dry weight for the LVt group $(7.0 \pm 0.3)$ was similar to the APRV group (7.6 $\pm 0.9 ; p>0.05)$.

The lungs in the LVt group demonstrated a significant increase in alveolar wall thickening as compared with APRV ( $p<0.05$; Fig. 3). There was also a significant increase in intra-alveolar hemorrhage in the LVt group as compared with APRV $(p<0.05)$, with the luminal erythrocytes noted to be intact with no signs of hemolysis. Although not statistically significant, LVt had a relative increase in vessel congestion (Fig. 3), atelectasis, and fibrinous deposits $(p>0.05)$.

\section{Bronchoalveolar lavage}

There was a trend towards an increase in total protein in the BALF in the LVt group $\left(1271.5 \pm 590.6 \mu \mathrm{g} \mathrm{mL} L^{-1}\right)$ as compared with APRV $\left(300.9 \pm 9.8 \mu \mathrm{g} \mathrm{mL} L^{-1}\right)$ although this

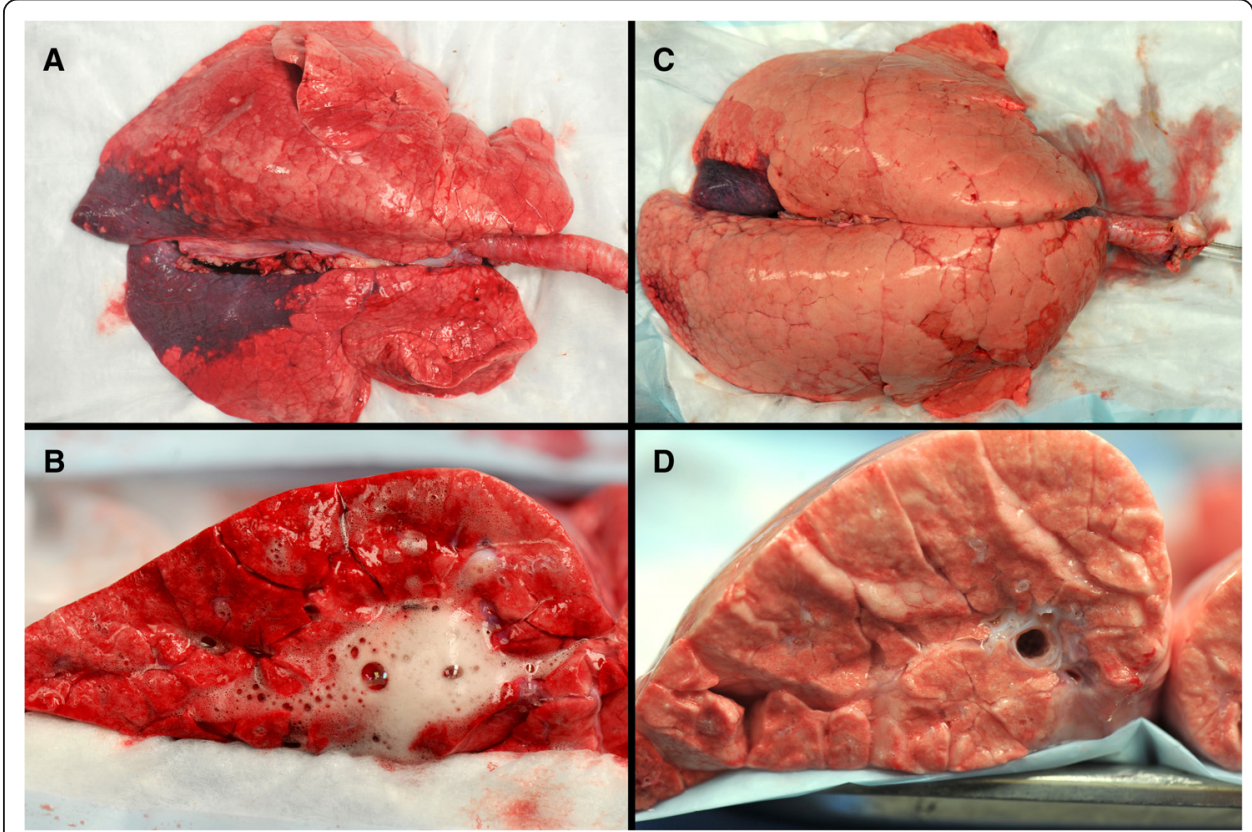

Fig. 2 Low tidal volume ventilation lungs (a) inflated heterogeneously with prominent dependent and basilar atelectasis and the cut surface (b) revealing airway edema. Airway Pressure Release Ventilation gross lungs (c) and cut surface (d) were pink, light and inflated homogeneously without airway edema 


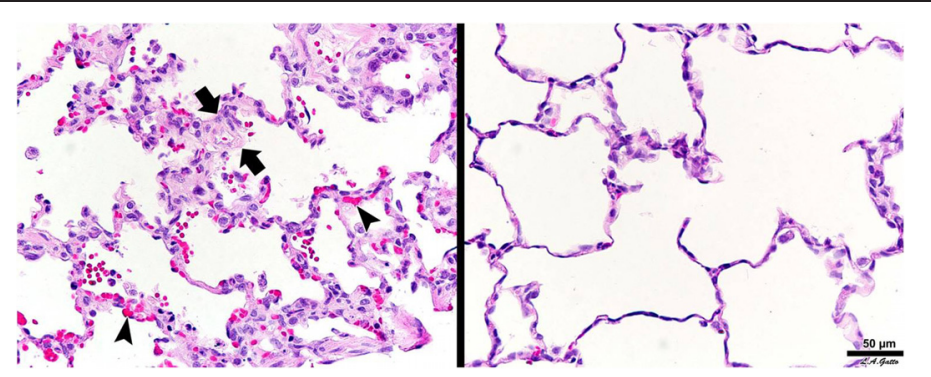

Fig. 3 Low tidal volume (LVt; left) demonstrated increased alveolar wall thickness (between arrows) and vessel congestion (arrowheads) as compared with Airway Pressure Release Ventilation (APRV; right)

did not reach statistical significance $(p=0.18)$. SP-A in the BALF was significantly reduced in the LVt group as compared with APRV $(p<0.05)$ although SP-B was not significantly different between the two groups $(p=0.09)$. The BALF concentrations of IL-8 were similar between LVt $\left(145.8 \pm 115.5 \mathrm{pg} \mathrm{mL}^{-1}\right)$ and APRV $\left(79.4 \pm 56.6 \mathrm{pg} \mathrm{mL}^{-1}\right.$; $p>0.05)$. The BALF concentrations of IL- 6 was relatively greater in the LVt group $\left(2677 \pm 1060 \mathrm{pg} \mathrm{mL}^{-1}\right)$ as compared with APRV $\left(342.1 \pm 146.9 \mathrm{pg} \mathrm{mL}^{-1} ; p>0.05\right)$.

\section{Discussion}

The transpulmonary pressure between APRV and LVt, however, was similar suggesting that the $P_{\text {plat }}$ and $V_{\mathrm{t}}$ in APRV did not lead to increased lung stress. This is in spite of the fact that the APRV group was associated with an elevated $P_{\text {plat }}$ and greater $V_{\mathrm{t}}$, as compared with LVt, both of which are currently considered injurious [3]. Thus, the majority of the plateau pressure in the APRV group was being distributed as pleural pressure, applied to the chest wall, an important finding in this extrapulmonary lung injury model associated with increased chest wall elastance. In addition, APRV preserved surfactant protein-A concentrations and reduced epithelial permeability, as measured by BALF protein. APRV also preserved lung elastance and reduced lung injury by histopathologic scoring.

\section{Intra-abdominal pressure and chest wall elastance}

ARDS can be largely subdivided by its original etiology: pulmonary (i.e., pneumonia and aspiration) and extrapulmonary (i.e., sepsis, hemorrhage, peritonitis, systemic inflammatory response syndrome, and multi-organ trauma). Although the two ARDS phenotypes may have similar pathophysiologic outcomes, the pathogenesis and treatment are different [1]. Whereas increased lung and respiratory system elastance is found in both pulmonary and extrapulmonary ARDS, an increase in chest wall elastance is primarily associated with extrapulmonary ARDS [1]. The chest wall consists of the anterior and posterior thoracic cage and the diaphragm, which serves as a pliable separation between the abdominal and thoracic cavities [31]. Approximately half of the IAP is transmitted to the intrathoracic space [31, 32]; thus, increased IAP is one of the most common causes of increased chest wall elastance in extrapulmonary ARDS and has been associated with increased pulmonary edema, atelectasis, and lung neutrophil activation [19]. Body wall edema can further increase elastance of both the chest wall and abdomen [33].

Intra-abdominal hypertension has been observed in $54.4 \%$ of medical and $65.0 \%$ of surgically critically ill patients [18]. The IAP at end-inspiration has been shown to be 
approximately four times greater in the surgical ARDS groups as compared with the medical ARDS group [34]. An increase in IAP transmits stress to the thoracic cavity causing a decrease in functional residual capacity, ventilation-perfusion mismatching, a shift in the volume-pressure curve of the chest to the right, and compression atelectasis [31, 32, 34, 35]. The negative effects of increased IAP on the thoracic cavity can be attenuated by increasing the pleural pressure, effectually placing an opposing force on the IAP [36, 37]. Since pleural pressure and IAP have a linear relationship [1], the combination of a prolonged inspiratory time and increased pleural pressure in the APRV group further increased the measured IAP [38] and is likely the mechanism of decreased chest wall elastance in this group.

Despite the increase in IAP, APRV improved lung elastance while maintaining a physiologic $\mathrm{P}_{\mathrm{a}} \mathrm{O}_{2} / \mathrm{F}_{\mathrm{i}} \mathrm{O}_{2}$ ratio. The importance of delivering a pressure sufficient to shift the volume-pressure curve of the chest back to the left and increase diaphragm tension at end-expiration to prevent the negative effects of IAP transmission to the chest wall was established in a study of increasing PEEP [39]. In the current study, the extended time at the $P_{\text {plat }}$ in the APRV group similarly opposed the effects of increased IAP. Conversely, the lungs of the LVt pigs universally had bibasilar atelectasis suggesting that the PEEP scale guided by the ARDSnet protocol was insufficient to oppose the force of the IAP on the lower lung lobes. This is supported by the significant increase in lung elastance in the LVt group by $48 \mathrm{~h}$, and the trend suggested that the lung elastance would have increased further had the animals not reached the termination point of the study.

\section{Plateau pressure versus pleural pressure}

As the IAP increases and the chest wall becomes stiffer, more of the $P_{\text {plat }}$ is generated as $P_{\mathrm{pl}}$ rather than $P_{1}[19,33,40]$. In patients with high $E_{\mathrm{cw}}$, limiting $P_{\mathrm{plat}}$ could worsen oxygenation and enable lung derecruitment if the transpulmonary pressure is not considered, whereas an appropriately high plateau pressure could improve oxygenation and lung/ chest wall elastance [40]. In a porcine model by Kubiak et al. [33], pneumoperitoneum was established and, as IAP increased, $P_{\text {plat }}$ and $P_{\mathrm{pl}}$ increased but $P_{1}$ did not, whereas ventilating to similar $P_{\text {plat }}$ in a desufflated abdomen led to a significant increase in $P_{1}$. Thus, that study demonstrates that in a patient population with a compromised chest wall, $P_{\text {plat }}$ is a poor surrogate for $P_{\mathrm{l}}$, and setting the upper limit for $P_{\text {aw }}$ at $30 \mathrm{cmH}_{2} \mathrm{O}$ may not be realistic without considering the underlying chest wall mechanics [33].

In patients with influenza A (H1N1)-induced ARDS referred for extracorporeal membrane oxygenation (ECMO), Grasso et al. [41] determined that there was a subset of patients in whom the majority of pressure applied by the ventilator was being transmitted to the stiff chest wall rather than to recruiting the lung [41]. The authors determined that targeting end-inspiratory $P_{1}$ rather than the respiratory system $P_{\text {plat }}$ significantly improved patient oxygenation such that $50 \%$ of patients that previously met ECMO criteria no longer did [41]. In this current study, the LVt pig that achieved a $P_{\text {plat }}$ greater than $30 \mathrm{cmH}_{2} \mathrm{O}$ had a corresponding $P_{1}$ of $23.4 \mathrm{cmH}_{2} \mathrm{O}$ and dropping the tidal volumes to accommodate the $P_{\text {plat }}$ led to prompt desaturation.

It has previously been demonstrated in an in vivo study that APRV, with an extended time at the $P_{\text {plat }}$, improves alveolar recruitment and alveolar surface area, suggesting that these larger tidal volumes are being distributed over a greater number of open 
alveoli, reducing the dynamic strain on individual alveoli [42]. In a prospective study by Chiumello et al. [43], comparing control patients with those with acute lung injury or ARDS, increasing PEEP from 5 to $15 \mathrm{cmH}_{2} \mathrm{O}$ led to a decrease in lung, chest wall, and respiratory system elastance. Additional time at a greater pressure (PEEP or plateau pressure) therefore allows for increased alveolar recruitment and distribution of the tidal volume over a larger surface area of alveoli, reducing overall lung stress. Protective mechanical ventilation should be instituted early and consideration given towards increasing PEEP or extending time at the $P_{\text {plat }}$ to optimize recruitment while limiting the potential negative effects of larger $V_{\mathrm{t}}$.

\title{
Conclusions
}

In this study, we have demonstrated that the early application of APRV improves oxygenation and maintains surfactant as compared with LVt applied immediately following injury. APRV had greater plateau pressures and tidal volumes as compared with LVt yet the transpulmonary pressures between the groups were similar. Thus, APRV represents a safe and effective ventilation mode in patients at risk for the development of extrapulmonary lung injury.

\begin{abstract}
Abbreviations
ARDS: acute respiratory distress syndrome; APRV: airway pressure release ventilation; $L V_{t}$ : low tidal volume ventilation; $E_{\mathrm{cw}}$ : chest wall elastance; $E_{\mathrm{rs}}$ : respiratory system elastance; $E_{\mathrm{j}}$ : lung elastance; IACUC: Institutional Animal Care and Use Committee; $V_{t}$ : tidal volume; PEEP: positive end-expiratory pressure; RR: respiratory rate; IAP: intra-abdominal pressure; BL: baseline; T0: time zero; $P_{\text {plat: }}$ plateau pressure; $P_{1}$ : transpulmonary pressure; $P_{\text {pl: }}$ pleural pressure; $\Delta P_{\text {es: }}$ : change in esophageal pressure; BALF: bronchoalveolar lavage fluid; SP-A: surfactant protein A; SP-B: surfactant protein B.
\end{abstract}

\section{Competing interests}

This project was supported by the Upstate Medical University HSC Foundation account. Voluntary donations were accepted into this fund. Donors waived rights to determine how and to which projects the funds were allocated. Donations were accepted under the condition that ownership of intellectual property rights was waived and donor approval not required for publication. These funds were not provided for goods or services.

\section{Authors' contributions}

MKS drafted the manuscript and participated in data collection and interpretation. BE, JL, EP, VK, and GW participated in the data collection and interpretation. SVJ, JS, LAG, and GFN critically revised the manuscript and participated in the data collection and interpretation. PA helped to conceive, draft, and critically revise the manuscript and participated in the data collection and interpretation. WM critically revised the manuscript. NMH helped to conceive, draft, and critically revise the manuscript and participated in the data collection and interpretation. All authors read and approved the final manuscript.

\section{Author details}

${ }^{1}$ Department of Surgery, SUNY Upstate Medical University, 750 E. Adams Street, Syracuse, NY 13210, USA. ²Department of Trauma Critical Care Medicine, R Adams Cowley Shock Trauma Center, University of Maryland School of Medicine, Baltimore, MD, USA. ${ }^{3}$ Department of Biological Sciences, SUNY Cortland, Cortland, NY, USA.

Received: 14 September 2015 Accepted: 13 December 2015

Published online: 22 December 2015

\section{References}

1. Gattinoni L, Pelosi P, Suter PM, Pedoto A, Vercesi P, Lissoni A (1998) Acute respiratory distress syndrome caused by pulmonary and extrapulmonary disease. Different syndromes? Am J Respir Crit Care Med 158(1):3-11

2. Brower RG, Lanken PN, Macintyre N et al. (2004) Higher versus lower positive end-expiratory pressures in patients with the acute respiratory distress syndrome. N Engl J Med 351(4):327-336

3. The Acute Respiratory Distress Syndrome Network. Ventilation with Lower Tidal Volumes as Compared with Traditional Tidal Volumes for Acute Lung Injury and the Acute Respiratory Distress Syndrome. N Engl J Med. 2000; 342:1301-8.

4. Mercat A, Richard JC, Vielle B et al. (2008) Positive end-expiratory pressure setting in adults with acute lung injury and acute respiratory distress syndrome: a randomized controlled trial. JAMA 299(6):646-655

5. Young D, Lamb SE, Shah S et al. (2013) High-frequency oscillation for acute respiratory distress syndrome. N Engl J Med 368(9):806-813

6. Ferguson ND, Cook DJ, Guyatt GH et al. (2013) High-frequency oscillation in early acute respiratory distress syndrome. N Engl J Med 368(9):795-805 
7. Meade MO, Cook DJ, Guyatt GH et al. (2008) Ventilation strategy using low tidal volumes, recruitment maneuvers, and high positive end-expiratory pressure for acute lung injury and acute respiratory distress syndrome: a randomized controlled trial. JAMA 299(6):637-645

8. Villar J, Blanco J, Anon JM et al. (2011) The ALIEN study: incidence and outcome of acute respiratory distress syndrome in the era of lung protective ventilation. Intensive Care Med 37(12):1932-1941

9. Staffieri F, Stripoli T, De Monte $V$ et al. (2012) Physiological effects of an open lung ventilatory strategy titrated on elastance-derived end-inspiratory transpulmonary pressure: study in a pig model*. Crit Care Med 40(7):2124-2131

10. Gattinoni L, Vagginelli F, Chiumello D, Taccone P, Carlesso E (2003) Physiologic rationale for ventilator setting in acute lung injury/acute respiratory distress syndrome patients. Crit Care Med 31(4 Suppl):S300-S304

11. Roy S, Habashi N, Sadowitz B et al. (2013) Early airway pressure release ventilation prevents ARDS—a novel preventive approach to lung injury. Shock 39(1):28-38

12. Roy S, Sadowitz B, Andrews P et al. (2012) Early stabilizing alveolar ventilation prevents acute respiratory distress syndrome: a novel timing-based ventilatory intervention to avert lung injury. J Trauma Acute Care Surgery 73(2):391-400

13. Cheatham ML, Malbrain ML, Kirkpatrick A et al. (2007) Results from the International Conference of Experts on Intra-abdominal Hypertension and Abdominal Compartment Syndrome. II. Recommendations. Intensive Care Med 33(6):951-962

14. Baydur A, Behrakis PK, Zin WA, Jaeger M, Milic-Emili J (1982) A simple method for assessing the validity of the esophageal balloon technique. Am Rev Respir Dis 126(5):788-791

15. Kubiak BD, Albert SP, Gatto LA et al. (2011) A clinically applicable porcine model of septic and ischemia/ reperfusion-induced shock and multiple organ injury. J Surg Res 166(1):e59-e69

16. Habashi NM (2005) Other approaches to open-lung ventilation: airway pressure release ventilation. Crit Care Med 33(3 Suppl):S228-S240

17. Dellinger RP, Levy MM, Rhodes A et al. (2013) Surviving sepsis campaign: international guidelines for management of severe sepsis and septic shock: 2012. Crit Care Med 41(2):580-637

18. Gattinoni L, Chiumello D, Carlesso E, Valenza F (2004) Bench-to-bedside review: chest wall elastance in acute lung injury/acute respiratory distress syndrome patients. Crit Care 8(5):350-355

19. Pelosi P, Luecke T, Rocco PR (2011) Chest wall mechanics and abdominal pressure during general anaesthesia in normal and obese individuals and in acute lung injury. Curr Opin Crit Care 17(1):72-79.19.

20. Akoumianaki E, Maggiore SM, Valenza F et al. (2014) The application of esophageal pressure measurement in patients with respiratory failure. Am J Respir Crit Care Med 189(5):520-531

21. Buytendijk H. Intraesophageal pressure and lung elasticity. Thesis. Groningen, Holland: University of Groningen, Electrusche Drukkerij I. Oppenheim N.V; 1949

22. D'Angelo E, Bonanni MV, Michelini S, Agostoni E (1970) Topography of the pleural pressure in rabbits and dogs. Respir Physiol 8(2):204-229

23. Agostoni E, Miserocchi G (1970) Vertical gradient of transpulmonary pressure with active and artificial lung expansion. J Appl Physiol 29(5):705-712

24. Mead J, Gaensler EA (1959) Esophageal and pleural pressures in man, upright and supine. J Appl Physiol 14(1):81-83

25. Stenqvist O, Grivans C, Andersson B, Lundin S (2012) Lung elastance and transpulmonary pressure can be determined without using oesophageal pressure measurements. Acta Anaesthesiol Scand 56(6):738-747

26. Cherniack RM, Farhi LE, Armstrong BW, Proctor DF (1955) A comparison of esophageal and intrapleural pressure in man. J Appl Physiol 8(2):203-211

27. Pelosi P, Goldner M, McKibben A et al. (2001) Recruitment and derecruitment during acute respiratory failure: an experimental study. Am J Respir Crit Care Med 164(1):122-130

28. Gulati G, Novero A, Loring SH, Talmor D (2013) Pleural pressure and optimal positive end-expiratory pressure based on esophageal pressure versus chest wall elastance: incompatible results*. Crit Care Med $41(8): 1951-1957$

29. Roy SK, Emr B, Sadowitz B et al. (2013) Preemptive application of airway pressure release ventilation prevents development of acute respiratory distress syndrome in a rat traumatic hemorrhagic shock model. Shock 40(3): 210-216

30. Force ADT, Ranieri VM, Rubenfeld GD et al. (2012) Acute respiratory distress syndrome: the Berlin Definition. JAMA 307(23):2526-2533

31. Malbrain ML, Deeren D, De Potter TJ (2005) Intra-abdominal hypertension in the critically ill: it is time to pay attention. Curr Opin Crit Care 11(2):156-171

32. Hess DR, Bigatello LM (2008) The chest wall in acute lung injury/acute respiratory distress syndrome. Curr Opin Crit Care 14(1):94-102

33. Kubiak BD, Gatto LA, Jimenez EJ et al. (2010) Plateau and transpulmonary pressure with elevated intra-abdominal pressure or atelectasis. J Surg Res 159(1):e17-e24

34. Ranieri VM, Brienza N, Santostasi S et al. (1997) Impairment of lung and chest wall mechanics in patients with acute respiratory distress syndrome: role of abdominal distension. Am J Respir Crit Care Med 156(4 Pt 1): 1082-1091

35. Rouby JJ, Puybasset L, Nieszkowska A, Lu Q (2003) Acute respiratory distress syndrome: lessons from computed tomography of the whole lung. Crit Care Med 31(4 Suppl):S285-S295

36. Pelosi P, Quintel M, Malbrain ML (2007) Effect of intra-abdominal pressure on respiratory mechanics. Acta Clin Belg Suppl 1:78-88

37. Regli A, Mahendran R, Fysh ET et al. (2012) Matching positive end-expiratory pressure to intra-abdominal pressure improves oxygenation in a porcine sick lung model of intra-abdominal hypertension. Crit Care 16(5):R208

38. Verzilli D, Constantin JM, Sebbane M et al. (2010) Positive end-expiratory pressure affects the value of intra-abdominal pressure in acute lung injury/acute respiratory distress syndrome patients: a pilot study. Crit Care 14(4):R137

39. Lundin S, Grivans C, Stenqvist O (2015) Transpulmonary pressure and lung elastance can be estimated by a PEEPstep manoeuvre. Acta Anaesthesiol Scand 59(2):185-196 
40. Loring SH, O'Donnell CR, Behazin N et al. (2010) Esophageal pressures in acute lung injury: do they represent artifact or useful information about transpulmonary pressure, chest wall mechanics, and lung stress? J Appl Physiol 108(3):515-522

41. Grasso S, Terragni P, Birocco A et al. (2012) ECMO criteria for influenza A (H1N1)-associated ARDS: role of transpulmonary pressure. Intensive Care Med 38(3):395-403

42. Kollisch-Singule M EB, Smith B, Roy S, Jain S, Satalin J, Snyder K, Andrews P, Habashi N, Bates J, Marx W, Nieman G, Gatto L. Mechanical breath profile of APRV maximizes alveolar recruitment and minimizes micro-strain in acute lung injury. JAMA Surg. 2014(In Press.).

43. Chiumello D, Carlesso E, Cadringher $P$ et al. (2008) Lung stress and strain during mechanical ventilation for acute respiratory distress syndrome. Am J Respir Crit Care Med 178(4):346-355

Submit your manuscript to a SpringerOpen ${ }^{\odot}$ journal and benefit from:

- Convenient online submission

- Rigorous peer review

- Immediate publication on acceptance

- Open access: articles freely available online

- High visibility within the field

- Retaining the copyright to your article

Submit your next manuscript at $\gg$ springeropen.com 